\title{
Microsurgical Clipping of Carotid-Ophthalmic Tandem Aneurysms: Case Report and Surgical Nuances
}

\author{
Matias Costa ${ }^{1}$, Matías Baldoncini ${ }^{2}$, Zachary L. Tataryn ${ }^{3}$, Mickaela Echavarria Demichelis ${ }^{2}$, Agustin Conde ${ }^{2}$, \\ Cynthia Purves ${ }^{4}\left(\mathbb{D}\right.$, Alice Giotta Lucifero ${ }^{5}$, Juha Hernesniemi ${ }^{6}$ and Sabino Luzzi ${ }^{5,7, *(1)}$ \\ 1 Cerebrovascular Neurosurgery Department, Swedish Neuroscience Institute, Seattle, WA 98122, USA; \\ matiascostamd@gmail.com \\ 2 Department of Neurological Surgery, Hospital San Fernando, Buenos Aires 1646, Argentina; \\ drbaldoncinimatias@gmail.com (M.B.); mickaelaechavarria@hotmail.com (M.E.D.); \\ ag_conde@hotmail.com (A.C.) \\ 3 Spine Department, Swedish Neuroscience Institute, Seattle, WA 98122, USA; zactataryn@gmail.com \\ 4 Division of Interventional Neuroradiology, Juan A. Fernandez Hospital and Güemes Clinic, \\ Buenos Aires C1425 CABA, Argentina; cynthiapurves@gmail.com \\ 5 Neurosurgery Unit, Department of Clinical-Surgical, Diagnostic and Pediatric Sciences, University of Pavia, \\ 27100 Pavia, Italy; alicelucifero@gmail.com \\ 6 Juha Hernesniemi International Center for Neurosurgery, Henan Provincial People's Hospital, \\ Zhengzhou 450003, China; juha.hernesniemi@icloud.com \\ 7 Neurosurgery Unit, Department of Surgical Sciences, Fondazione IRCCS Policlinico San Matteo, \\ 27100 Pavia, Italy \\ * Correspondence: sabino.luzzi@unipv.it
}

Citation: Costa, M.; Baldoncini, M.; Tataryn, Z.L.; Demichelis, M.E.; Conde, A.; Purves, C.; Giotta Lucifero, A.; Hernesniemi, J.; Luzzi, S. Microsurgical Clipping of Carotid-Ophthalmic Tandem Aneurysms: Case Report and Surgical Nuances. Medicina 2021, 57, 731. https://doi.org/10.3390/ medicina57070731

Academic Editor:

Vasileios Papavasileiou

Received: 12 May 2021

Accepted: 16 July 2021

Published: 19 July 2021

Publisher's Note: MDPI stays neutral with regard to jurisdictional claims in published maps and institutional affiliations.

Copyright: (c) 2021 by the authors. Licensee MDPI, Basel, Switzerland. This article is an open access article distributed under the terms and conditions of the Creative Commons Attribution (CC BY) license (https:/ / creativecommons.org/licenses/by/ $4.0 /)$.

Abstract: Tandem intracranial aneurysms (TandIAs) are rare but inherently complex, and special technical considerations are required for their surgical management. The present case highlights the key surgical aspects of two carotid-ophthalmic TandIAs incidentally found in a 60-year-old female. Both the aneurysms were superiorly projecting, regular in size, and involved the left ophthalmic segment of the internal carotid artery (ICA). The minimum distance between the necks was $3 \mathrm{~mm}$. The patient underwent microsurgery because of the reported major complications rate of the endovascular treatment in the case of a very short minimum distance between the TandIAs. After cervical ICA exposure, both the aneurysms were excluded through a pterional approach. Intradural anterior clinoidectomy and unroofing of the optic canal allowed the mobilization of the left optic nerve. The more distal aneurysm was clipped before the opening of the distal dural ring of the ICA. The proximal aneurysm was clipped with two straight clips stacked perpendicular to the ICA. A small remnant was intentionally left to avoid the stenosis of the ophthalmic artery. Postoperative angiography showed the exclusion of both the aneurysms with a small dog-ear of the more proximal one. The patient was discharged neurologically intact and, after one year, the remnant remained stable. Microsurgical clipping is a definitive and durable treatment for carotid-ophthalmic TandIAs. In the case of a very short minimum distance between the aneurysms, the distal one should be clipped first to make the anterior clinoidectomy, opening of the distal dural ring of the ICA, and clipping of the more proximal aneurysm easier.

Keywords: anterior clinoidectomy; carotid-ophthalmic aneurysms; clipping; flow-diverter; internal carotid artery; tandem intracranial aneurysms

\section{Introduction}

Multiple intracranial aneurysms have been reported to have a prevalence ranging between 15-35\% in the largest series [1-5]. Their incidence is similar across the countries worldwide but significantly higher in women, patients with autosomal dominant polycystic kidney disease, a family history of intracranial aneurysm and subarachnoid hemorrhage, brain tumor, pituitary adenoma, and atherosclerosis [5-7]. Tandem intracranial aneurysms 
(TandIAs) represent a specific angioarchitectural type, in which two aneurysms of at least $30 \mathrm{~mm}$ in maximal diameter are nearby on the same parent vessel or two separate but not interconnected adjacent arteries. Their pathogenesis remains unclear to date, although the segmental duplication of the parent artery, also known as "fenestration" and resulting from an embryonic error, has been linked with the incidence of TandIAs [8-14]. TandIAs involve the internal carotid artery (ICA) in $87 \%$ of cases, and specifically the ophthalmic (C6) segment according to Bouthillier classification in $50 \%$ of occurrences $[15,16]$. Other possible sites in decreasing order of frequency are the vertebral artery, middle cerebral artery, basilar artery, posterior inferior cerebellar artery, anterior cerebral artery, and anterior communicating artery [15,17-22]. TandIAs may also be "kissing" in the case of a partial adhesion between aneurysmal walls [23,24]. The frequency of TandIAs has been estimated to be up to $2.8 \%$ of all intracranial aneurysms $[25,26]$, and specific risk factors for their development, such as fenestrated arterial variants [27] and family history [28], have been suggested. In comparison with solitary aneurysms, TandIAs pose special challenges from the surgical and endovascular standpoints for several reasons: unpredictable hemodynamic effects which treating one aneurysm may have on the other one, technical difficulties associated with a possible "kissing" configuration, the need to balance the choice between single versus multiple treatment sessions, increased risk of complications resulting from the cumulative sum of morbidity rates associated with each aneurysm, and a relative lack of overall experience due to the very small number of cases reported in the literature. Accordingly, the best treatment strategy of TandIAs remains controversial despite the tremendous and constant improvement and refinement of endovascular and surgical techniques.

The purpose of this case report is to describe the technical nuances of the microsurgical management of two carotid-ophthalmic tandem aneurysms.

\section{Case Presentation}

A 60-year-old female with a history of systemic arterial hypertension was diagnosed with two incidental side-wall paraclinoid TandIAs of the left ICA after having undergone a 3D CT angiography due to an isolated transitory ischemic attack. Both the aneurysms were saccular, superiorly projecting, and involved the ophthalmic (C6) segment of the ICA. The size, aspect ratio, and flow angle were $8 \mathrm{~mm}, 1.5$, and $92^{\circ}$, respectively, in the proximal aneurysm, and $7 \mathrm{~mm}, 1.7$, and $110^{\circ}$ correspondingly in the distal one (Figure $1 \mathrm{~A}, \mathrm{~B}$ ). The minimum distance between the aneurysmal necks, namely the distance between the distal end of the proximal aneurysm and the proximal end of the distal one, measured $3 \mathrm{~mm}$. An MRI excluded intraluminal thromboses. Given the relatively small size of both aneurysms, the risk of intraoperative ICA sacrifice was considered negligible, and a balloon test occlusion was deemed unnecessary. Campimetry revealed a normal visual acuity, and oculomotion was intact. After a multidisciplinary neurovascular meeting, open surgical clipping of both aneurysms was decided.

The exposure of the cervical ICA was accomplished to achieve proximal control before performing a left standard pterional approach with the patient's head rotated $45^{\circ}$ to the right side and tilted $10^{\circ}$ in extension. Distal-to-proximal Sylvian fissure dissection was performed starting at the anterior Sylvian point. The Sylvian, carotid, optic, and chiasmatic cisterns were widely opened, and cerebrospinal fluid was released for brain relaxation. Both aneurysms were exposed in the left paraclinoid region. They presented multiple blebs, and the distal one showed a calcified neck. The left optic nerve was displaced by the proximal aneurysm. A left intradural anterior clinoidectomy and unroofing of the optic canal were performed with a $3 \mathrm{~mm}$ diamond drill. The falciform ligament was sharply divided to gently mobilize the optic nerve. A pilot clip was initially used for the distal aneurysm. Afterward, the opening of the distal dural ring was completed before the mobilization of the left ICA. This maneuver allowed for the visualization of the take-off of the left ophthalmic artery (OphA). Multiple clipping attempts of the proximal aneurysm were executed, each of which caused stenosis at the origin of the OphA. As a consequence, 
the proximal aneurysm was partially obliterated with two stacked $9 \mathrm{~mm}$ straight clips, and a small remnant was intentionally left. The distal aneurysm was definitively excluded with a $7 \mathrm{~mm}$ angulated clip before the removal of the pilot clip (Figure 2). Post-operative angiography confirmed the complete exclusion of the distal aneurysm and a small remnant of the proximal one (Figure 1C,D). The patient was discharged without deficit on the third post-operative day, and, on angiography performed at the first-year follow-up, the known remnant of the proximal aneurysm remained stable.
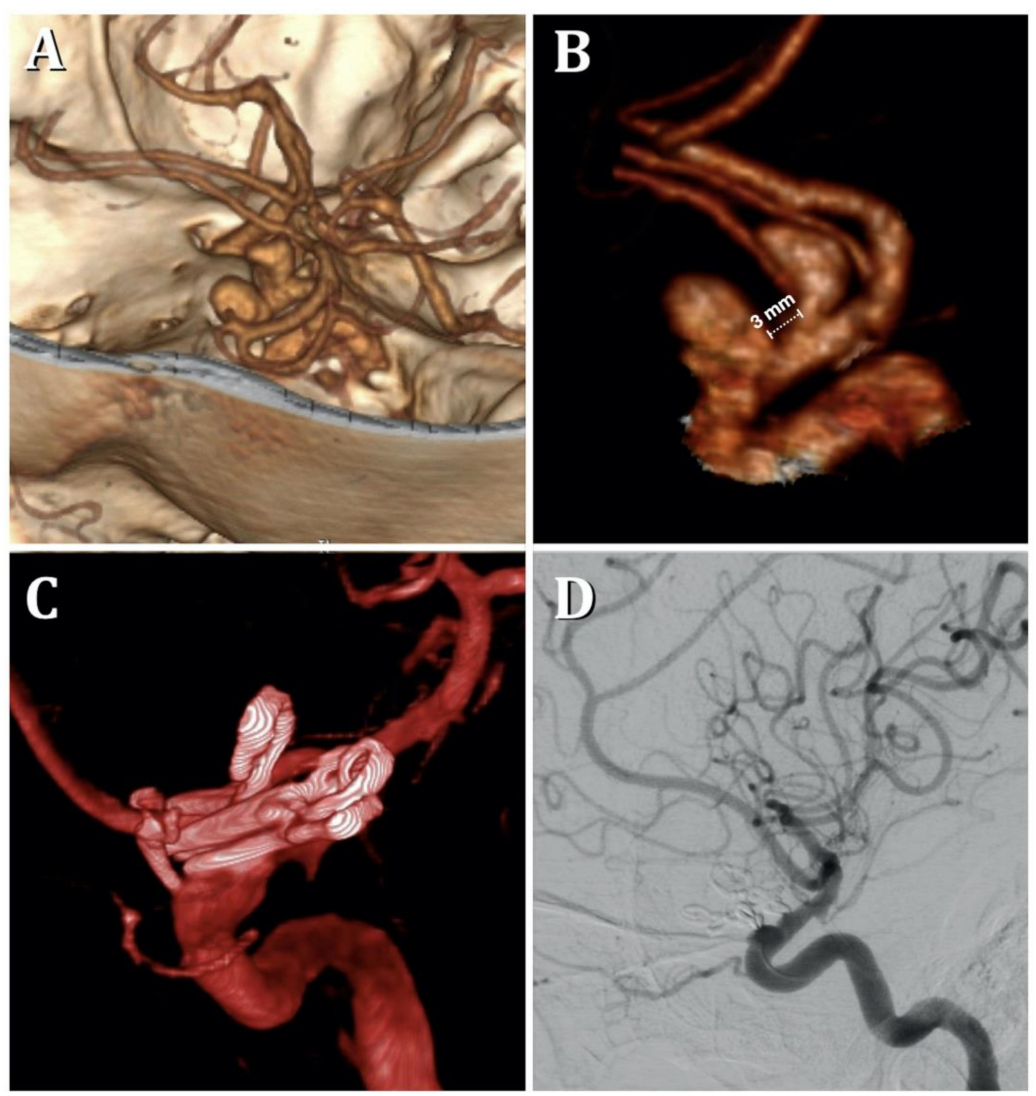

Figure 1. (A,B) Preoperative 3D CT angiography showing the left tandem paraclinoid internal carotid artery aneurysms. Postoperative 3D (C) and 2D (D) digital subtraction angiography in lateral projection.

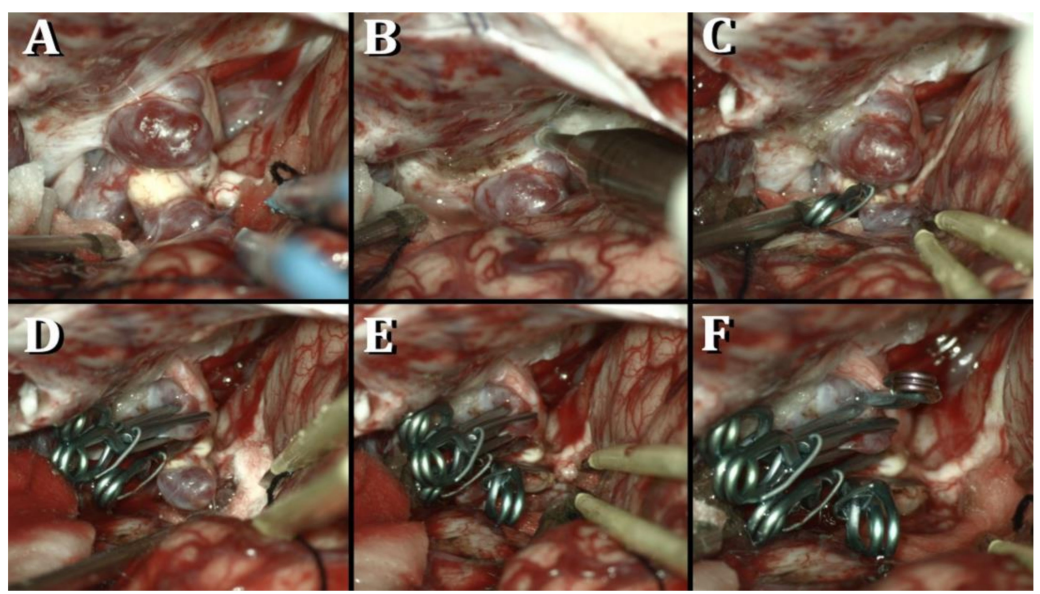

Figure 2. (A) Aneurysm's exposure; (B) anterior clinoidectomy; (C-F) clipping of the tandem paraclinoid internal carotid artery aneurysms. 


\section{Discussion}

The technical considerations of the microsurgical management of two ophthalmic tandem aneurysms of the ICA have been herein reported through the description of an illustrative case suggesting several points of discussion, the first of which is the reasons for the indication for surgery.

Literature about the management of TandIAs is largely based on very small series or even case reports, which implies a lack of universal recommendations about the management of these particular types of aneurysms. In the majority of cases, the indication for surgical or endovascular treatment is primarily based on the experience of the treating team.

In the present case, microneurosurgery was considered the best treatment option because of several factors set out below. The largest series (145 patients) about the endovascular treatment of TandIAs reported by Feng and colleagues proved that a shorter minimum distance between the aneurysms, multiple-session treatment, and diabetes were independent predictors of treatment-related complications, a lower occlusion rate, and a poor outcome on multivariate regression analysis [15]. Especially regarding the short minimum distance between the aneurysms, similar data were reported by Mut and colleagues based on a computational model [29]. It should be highlighted that in the reported case, the short minimum distance between the neck of the aneurysms was just $3 \mathrm{~mm}$. A further point in favor of microsurgery was the involvement of the OphA, whose occlusion risk by the side of the flow diverting stents rests unclear [30-38]. Adeeb et al. also stressed as larger aneurysms size negatively affects the occlusion rate of TandIAs treated with a single pipeline embolization device [19].

Despite the patient had suffered from a transitory ischemic attack, microneurosurgery was considered not at a greater risk of complications compared with endovascular treatment. In fact, in a multicenter clinical study, Qureshi and colleagues demonstrated an equal risk of major stroke between the surgical and conservative treatment [39]. Similar data were reported by McLaughlin et al. [40].

This treatment paradigm also comes from the authors' experience in the elective surgical management of isolated paraclinoid aneurysms. Current indications for microneurosurgery of paraclinoid aneurysms in the endovascular era include broad-based large and giant ophthalmic aneurysms in young patients, prohibitive tortuosity of the cervical ICA, resistance to aspirin, or clopidogrel/prasugrel, warning syndromes, and patient preference. As a consequence of their proximity, a single-stage pipeline procedure has been suggested as the best choice for two or even more TandIAs arising from the same parent vessel [17-21,41,42]. Nevertheless, the reported overall aneurysmal occlusion following pipeline and coil embolization is $58.8 \%$ and $77.4 \%$, respectively [15], and these rates are largely inferior to those of the treated solitary aneurysms with similar sizes and locations. Not surprisingly, multiple endovascular treatment sessions are associated with a worse outcome as a consequence of the cumulative morbidity risk [15]. These factors put into question the theoretical advantages of the endovascular treatment of tandem paraclinoid aneurysms. A further issue regards the full versus partial treatment in those cases where one of the two (or more) TandIAs finds no indication for treatment because of small size $(<5 \mathrm{~mm})$. The overall risk of complications seems to not be increased for endovascular therapy if the minimum distance between the aneurysms is greater than $5 \mathrm{~mm}$ [15]. Conversely, no conclusive data are reported in the literature in regards to the microsurgical clipping of TandIAs.

Based on the reported pieces of evidence, the surgical risk of solitary paraclinoid aneurysms is higher in the case of giant sizes, thrombosis, or heavily calcified neck. In these cases, bypass ought to be considered [43-45]. A further adjunctive risk may come from the necessity to treat a blister-like aneurysm of the ICA given their aggressive natural history, morbidity, and mortality [46-52]. In the case of large or giant aneurysms, a balloon test occlusion of the parent vessel and is mandatory, and angiography may provide precious details to consider during treatment planning. The proximal control of the ICA for temporary occlusion is mandatory for tandem paraclinoid aneurysms, likewise to what 
is required in paraclinoid aneurysms at large. Different techniques are today available for this purpose. They comprehend cervical or petrous ICA exposure, extradural or intradural clinoid ICA exposure, endovascular control with balloon-assisted occlusion or suction decompression (Dallas technique), adenosine-induced cardiac standstill, and intracavernous control [53-62]. Each of these techniques has advantages and disadvantages. The exposure of the petrous ICA may be challenging or ineffective [61,63-66]. Endovascular control im-poses an additional endovascular team or hybrid operative room and is not free from a non-negligible risk of embolic strokes and intimal dissection. Cardiac standstill has been reported to be burdened by a high mortality and morbidity rate. Intracavernous control, according to Krisht's technique, is an elegant and valuable option. Nevertheless, it needs extensive experience along with perfect knowledge of the microsurgical anatomy of the cavernous sinus. Because of their reliability, the techniques of exposure of the cervical and clinoid segments of the ICA are still today the most utilized by a large part of surgeons, including the authors. While admitting the high reliability of the extradural and intradural exposure of the clinoid segment of the ICA for the majority of small and regular paraclinoid aneurysms, we often prefer the cervical ICA in large, giant, and complex ones because of a theoretically higher risk of rupture during the anterior clinoidectomy. Considering their inherent complexity, tandem paraclinoid aneurysms as that herein reported fall into this group. A further aspect regards the reported higher risk of visual morbidity for carotid cave aneurysms and the temporary occlusion of the ICA executed at the level of the carotid cave [67]. From a technical standpoint, the surgical management of paraclinoid TandIAs in a single stage involves some additional difficulties in comparison with solitary aneurysms. A critical surgical decision arises in planning to treat the proximal or distal aneurysm first. We believe distal aneurysms ought to be excluded before attempts at proximal aneurysm occlusion for two reasons: First, a lower inflow rate, flow velocity, and wall shear stress in the more distal aneurysm affects the convex side of the ICA [29], making it less prone to intraoperative rupture. Second, the clipping of the clinoidal or ophthalmic aneurysms imposes the need for an anterior clinoidectomy, the opening of the distal dural ring, and mobilization of the ICA to allow for an effective clip placement. This avoids the sling effect and minimizes the risk of ICA stenosis after clipping [44]. All these maneuvers are hampered and complicated by the presence of a further distal aneurysm of the ophthalmic (C6) or communicating (C7) segment of the ICA [16]. Large or giant aneurysms of the dorsal ICA wall could also hinder the so-called "clinoidal cone" [68]. It must be stressed that "kissing" TandIAs represent an exception since the dissection at the "kissing point" and clipping of the distal aneurysm involves a tremendous risk of rupture of the proximal one, as reported by Yasargil [46]. A short distance between the necks of tandem aneurysms represents a challenging factor also for both microsurgical clipping and endovascular therapy. For both superior and inferior projecting aneurysms, tandem clipping and counter clipping in a cross-wise fashion is often technically impossible because the length of the clip line created by the blades of the overlapping clip is generally insufficient to exclude both the necks. Counterclipping in a "facing" fashion is certainly more suitable (Figure 3).

A good option to avoid the footprint of the clips is the use of stacked clips having an orientation perpendicular to the long axis of the ICA, as performed in our reported case. The parallel stacked clips are particularly useful in case of the shorter distance between the aneurysms. In the case of TandIAs having different projections, more complex clipping techniques are necessary. Our and other groups have previously stressed the role of indocyanine green and fluorescein video angiography, micro-Doppler ultrasonography, Doppler flowmetry, endoscopic assistance, and intraoperative digital subtraction angiography in neurovascular surgery [69-79], and we believe these tools prove critical in the management of TandIAs.

It must be stressed that larger series of TandIAs are necessary to validate the technical tips used in the management of the present case. 


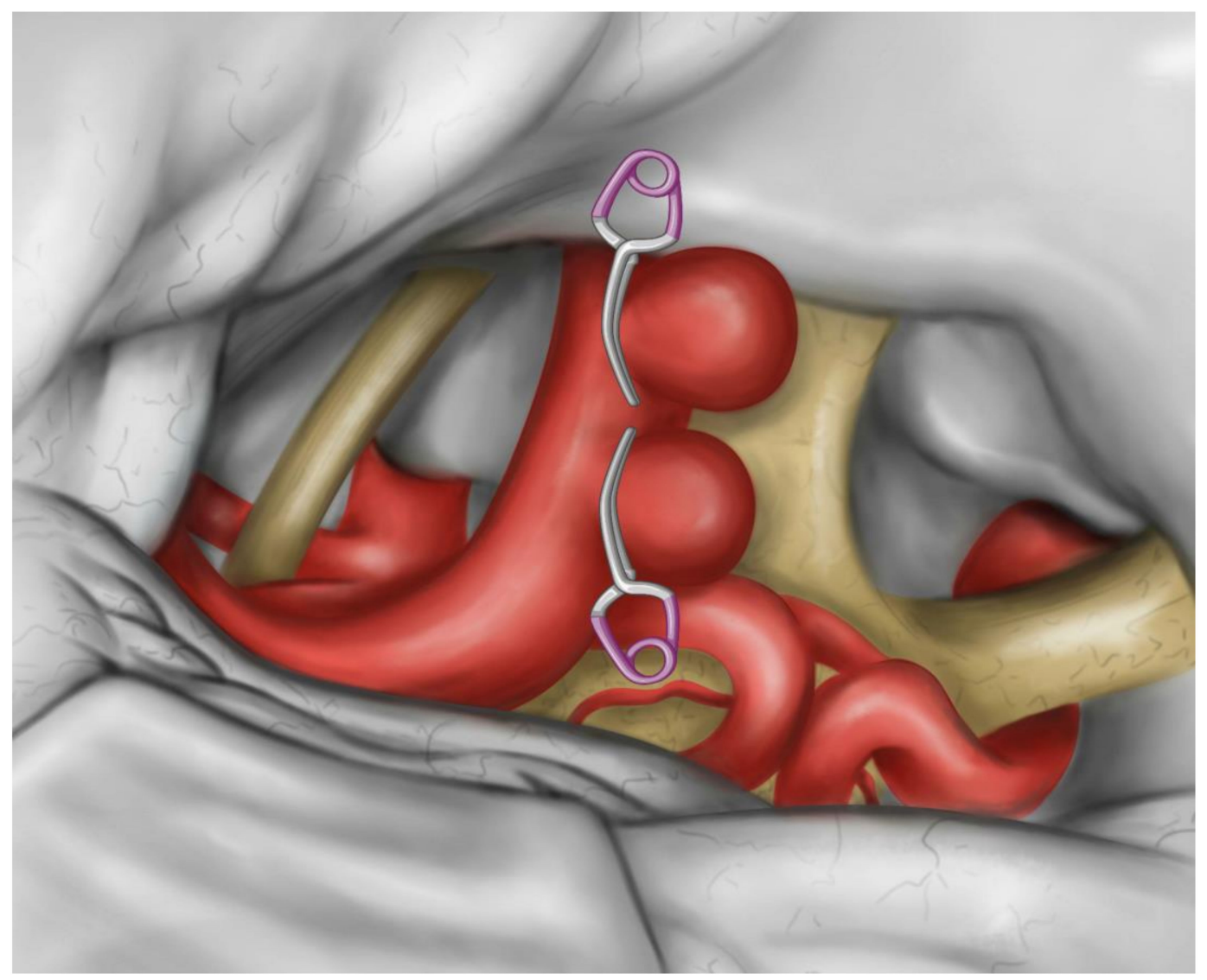

Figure 3. A sketch of counterclipping in the "facing" fashion.

\section{Conclusions}

Microsurgical clipping is a definitive and durable treatment for carotid-ophthalmic tandem aneurysms. The bypass option ought to be considered for very large and giant heavily thrombosed aneurysms.

Anterior clinoidectomy and opening of the distal dural ring are key aspects for paraclinoid TandIAs involving the clinoidal and ophthalmic segment of the ICA. The more distal aneurysm should be clipped first, except for "kissing" aneurysms, for which the risk of intraoperative rupture is higher.

A shorter minimum distance between TandIAs represents an adjunctive technical difficulty for both endovascular therapy and surgery, but counter clipping with "facing" clips and clipping with stacked clips parallel to the ICA allows overcoming this limitation during microsurgical treatment.

Author Contributions: Conceptualization, S.L., M.C. and M.B.; methodology, M.B.; software, Z.L.T.; validation, S.L. and J.H.; formal analysis, M.E.D.; investigation, A.C. and C.P.; resources, M.C.; data curation, A.G.L.; writing-original draft preparation, S.L., M.C. and M.B.; writing-review and editing, S.L.; visualization, A.G.L.; supervision, J.H.; project administration, M.B. All authors have read and agreed to the published version of the manuscript.

Funding: This research received no external funding.

Institutional Review Board Statement: The study was conducted according to the guidelines of the Declaration of Helsinki and approved by the Institutional Review Board.

Informed Consent Statement: Written informed consent has been obtained from the patient to publish this paper.

Data Availability Statement: Data are contained within the article. 
Acknowledgments: We want to thank Giuseppe Rizzo, a generous and high human value person, who decided to fund this article to help the Research advances and the patients suffering from neurovascular pathologies.

Conflicts of Interest: The authors declare no conflict of interest.

\section{References}

1. Vajda, J. Multiple intracranial aneurysms: A high risk condition. Acta Neurochir. 1992, 118, 59-75. [CrossRef]

2. Rinne, J.; Hernesniemi, J.; Puranen, M.; Saari, T. Multiple intracranial aneurysms in a defined population. Neurosurgery 1994, 35, 803-808. [CrossRef]

3. Østergaard, J.R.; Høg, E.; Østergaard, J.R.; Høg, E. Incidence of multiple intracranial aneurysms. J. Neurosurg. 1985, 63, 49-55. [CrossRef] [PubMed]

4. Inagawa, T. Incidence and risk factors for multiple intracranial saccular aneurysms in patients with subarachnoid hemorrhage in Izumo City, Japan. Acta Neurochir. 2009, 151, 1623-1630. [CrossRef] [PubMed]

5. Kaminogo, M.; Yonekura, M.; Shibata, S. Incidence and outcome of multiple intracranial aneurysms in a defined population. Stroke 2003, 34, 16-21. [CrossRef] [PubMed]

6. Turan, N.; Heider, R.A.-J.; Zaharieva, D.; Ahmad, F.U.; Barrow, D.; Pradilla, G. Sex differences in the formation of intracranial aneurysms and incidence and outcome of subarachnoid hemorrhage: Review of experimental and human studies. Transl. Stroke Res. 2015, 7, 12-19. [CrossRef] [PubMed]

7. Vlak, M.H.; Algra, A.; Brandenburg, R.; Rinkel, G.J. Prevalence of unruptured intracranial aneurysms, with emphasis on sex, age, comorbidity, country, and time period: A systematic review and meta-analysis. Lancet Neurol. 2011, 10, 626-636. [CrossRef]

8. Ichikawa, T.; Miyachi, S.; Izumi, T.; Matsubara, N.; Naito, T.; Haraguchi, K.-I.; Wakabayashi, T.; Koketsu, N. Fenestration of a supraclinoid internal carotid artery associated with dual aneurysms: Case report. Neurosurgery 2011, 69, E1005-E1009. [CrossRef]

9. Lasjaunias, P.; Santoyo-Vazquez, A. Segmental agenesis of the internal carotid artery: Angiographic aspects with embryological discussion. Surg. Radiol. Anat. 1984, 6, 133-141. [CrossRef]

10. Black, S.P.W.; Ansbacher, L.E. Saccular aneurysm associated with segmental duplication of the basilar artery. J. Neurosurg. 1984, 61, 1005-1008. [CrossRef]

11. Banach, M.J.; Flamm, E.S. Supraclinoid internal carotid artery fenestration with an associated aneurysm. J. Neurosurg. 1993, 79, 438-441. [CrossRef] [PubMed]

12. Takahashi, M.; Tamakawa, Y.; Kishikawa, T.; Kowada, M. Fenestration of the basilar artery. Report of three cases and review of the literature. Radiology 1973, 109, 79-82.

13. Yock, D.H. Fenestration of the supraclinoid internal carotid artery with rupture of associated aneurysm. Am. J. Neuroradiol. 1984, 5 .

14. Ng, P.P.; Steinfort, B.; Stoodley, M. Internal carotid artery fenestration with dual aneurysms. J. Neurosurg. 2006, 104, 979. [CrossRef] [PubMed]

15. Feng, X.; Tong, X.; Peng, F.; Wang, K.; Niu, H.; Qi, P.; Lu, J.; Wu, Z.; Chen, G.; Liu, A.; et al. The minimum distance may affect perioperative complications and completed occlusions of endovascular treatment for tandem intracranial aneurysms: A multi-institutional retrospective study. Cerebrovasc. Dis. 2020, 49, 609-618. [CrossRef]

16. Bouthillier, A.; Van Loveren, H.R.; Keller, J.T. Segments of the internal carotid artery: A new classification. Neurosurgery 1996, 38, 425-433. [CrossRef]

17. John, S.; Bain, M.; Cerejo, R.; Bauer, A.; Masaryk, T.; Hussain, M.S.; Rasmussen, P.; Toth, G. Flow diverter treatment of tandem intracranial aneurysms. World Neurosurg. 2017, 107, 142-147. [CrossRef]

18. Awad, A.-W.; Moon, K.; Yoon, N.; Mazur, M.D.; Kalani, M.Y.S.; Taussky, P.; McDougall, C.G.; Albuquerque, F.C.; Park, M.S. Flow diversion of tandem cerebral aneurysms: A multi-institutional retrospective study. Neurosurg. Focus 2017, 42, E10. [CrossRef] [PubMed]

19. Adeeb, N.; Moore, J.; Griessenauer, C.; Foreman, P.; Shallwani, H.; Dmytriw, A.; Shakir, H.; Siddiqui, A.; Levy, E.; Davies, J.; et al. Treatment of tandem internal carotid artery aneurysms using a single Pipeline Embolization device: Evaluation of safety and efficacy. Am. J. Neuroradiol. 2017, 38, 1605-1609. [CrossRef] [PubMed]

20. Fang, Y.-B.; Zhang, Z.; Yang, P.-F.; Wen, W.-L.; Hong, B.; Xu, Y.; Zhao, W.-Y.; Huang, Q.-H.; Liu, J.-M. Stepwise stent deployment technique for tandem intracranial aneurysms: A review of 21 cases. Eur. Radiol. 2015, 26, 351-358. [CrossRef] [PubMed]

21. Lin, N.; Brouillard, A.M.; Xiang, J.; Sonig, A.; Mokin, M.; Natarajan, S.K.; Krishna, C.; Hopkins, L.N.; Snyder, K.V.; Siddiqui, A.H.; et al. Endovascular management of adjacent tandem intracranial aneurysms: Utilization of stent-assisted coiling and flow diversion. Acta Neurochir. 2015, 157, 379-387. [CrossRef] [PubMed]

22. Abla, A.A.; Ducruet, A.F.; Spetzler, R.F.; Crowley, R.W.; McDougall, C.G.; Albuquerque, F.C. High-flow bypass and tandem microsurgical-endovascular occlusion of recurrent proximal middle cerebral artery aneurysms in a pediatric patient. J. Neurosurg. Pediatr. 2012, 10, 365-369. [CrossRef]

23. Harada, K.; Orita, T.; Ueda, Y. Large kissing aneurysms of the middle cerebral artery: A case report-Classification of kissing aneurysms. No. Shinkei. Geka. 2004, 32.

24. Jagetia, A.; Bhutte, M.; Aher, R.; Sinha, S.; Singh, D. Kissing aneurysm in a fenestrated mid-basilar arterial trunk: A case report and review of literature. Neurol. India 2013, 61, 437-439. [CrossRef] [PubMed] 
25. Yaşargil, M.G. Microneurosurgery: Clinical Considerations, Surgery of the Intracranial Aneurysms and Results; George Thieme/ThiemeStratton, Inc.: New York, NY, USA, 1984.

26. Kojima, T.; Waga, S. More than one aneurysm on the same artery. Surg. Neurol. 1984, 22, 403-408. [CrossRef]

27. Saatci, I.; Cekirge, H.; Karcaaltincaba, M.; Basgun, N.; Berker, M.; Timurkaynak, E.; Ozcan, O. Endovascular treatment of kissing aneurysms at the fenestrated basilar artery: Case report with literature review. Surg. Neurol. 2002, 58, 54-58. [CrossRef]

28. Jefferson, A. The significance for diagnosis and for surgical technique of multiple aneurysms of the same internal carotid artery. Acta Neurochir. 1978, 41, 23-37. [CrossRef]

29. Mut, F.; Scrivano, E.; Bleise, C.; Lylyk, P.; Cebral, J. Hemodynamics in two tandem aneurysms treated with flow diverters. Int. J. Numer. Methods Biomed. Eng. 2013, 30, 517-524. [CrossRef]

30. Moon, K.; Albuquerque, F.C.; Ducruet, A.F.; Crowley, R.W.; McDougall, C.G. Treatment of ophthalmic segment carotid aneurysms using the pipeline embolization device: Clinical and angiographic follow-up. Neurol. Res. 2014, 36, 344-350. [CrossRef]

31. Vedantam, A.; Rao, V.Y.; Shaltoni, H.M.; Mawad, M.E. Incidence and clinical implications of carotid branch occlusion following treatment of internal carotid artery aneurysms with the Pipeline Embolization device. Neurosurgery 2014, 76, 173-178. [CrossRef]

32. Chalouhi, N.; Daou, B.; Kung, D.; Zanaty, M.; Phillips, J.L.; Tjoumakaris, S.; Starke, R.M.; Hasan, D.; Polifka, A.; Salas, S.; et al. Fate of the ophthalmic artery after treatment with the Pipeline Embolization device. Neurosurgery 2015, 77, 581-584. [CrossRef]

33. Di Maria, F.; Pistocchi, S.; Clarençon, F.; Bartolini, B.; Blanc, R.; Biondi, A.; Redjem, H.; Chiras, J.; Sourour, N.; Piotin, M. Flow diversion versus standard endovascular techniques for the treatment of unruptured carotid-ophthalmic aneurysms. Am. J. Neuroradiol. 2015, 36, 2325-2330. [CrossRef] [PubMed]

34. Burrows, A.; Brinjikji, W.; Puffer, R.; Cloft, H.; Kallmes, D.; Lanzino, G. Flow diversion for ophthalmic artery aneurysms. Am. J. Neuroradiol. 2016, 37, 1866-1869. [CrossRef] [PubMed]

35. Rangel-Castilla, L.; Munich, S.A.; Jaleel, N.; Cress, M.C.; Krishna, C.; Sonig, A.; Snyder, K.V.; Siddiqui, A.H.; Levy, E.I. Patency of anterior circulation branch vessels after Pipeline Embolization: Longer-term results from 82 aneurysm cases. J. Neurosurg. 2017, 126, 1064-1069. [CrossRef]

36. Bhogal, P.; Ganslandt, O.; Bäzner, H.; Henkes, H.; Pérez, M.A. The fate of side branches covered by flow diverters-Results from 140 patients. World Neurosurg. 2017, 103, 789-798. [CrossRef]

37. Griessenauer, C.J.; Piske, R.L.; Baccin, C.E.; Pereira, B.J.; Reddy, A.S.; Thomas, A.J.; Abud, T.; Ogilvy, C.S. Flow diverters for treatment of 160 ophthalmic segment aneurysms: Evaluation of safety and efficacy in a multicenter cohort. Neurosurgery 2017, 80, 726-732. [CrossRef] [PubMed]

38. Puffer, R.C.; Kallmes, D.F.; Cloft, H.J.; Lanzino, G. Patency of the ophthalmic artery after flow diversion treatment of paraclinoid aneurysms. J. Neurosurg. 2012, 116, 892-896. [CrossRef]

39. Qureshi, A.; Mohammad, Y.; Yahia, A.M.; Luft, A.R.; Sharma, M.; Tamargo, R.J.; Frankel, M.R. Ischemic events associated with unruptured intracranial aneurysms: Multicenter clinical study and review of the literature. Neurosurgery 2000, 46, 282. [CrossRef] [PubMed]

40. McLaughlin, N.; Bojanowski, M.W. Unruptured cerebral aneurysms presenting with ischemic events. Can. J. Neurol. Sci. 2008, 35, 588-592. [CrossRef]

41. Bhogal, P.; Chudyk, J.; Bleise, C.; Lylyk, I.; Perez, N.; Henkes, H.; Lylyk, P. Treatment of unruptured, tandem aneurysms of the ica with a single flow diverter. Clin. Neuroradiol. 2018, 29, 725-731. [CrossRef]

42. Wang, C.; Tian, Z.; Liu, J.; Jing, L.; Paliwal, N.; Wang, S.; Zhang, Y.; Xiang, J.; Siddiqui, A.H.; Meng, H.; et al. Flow diverter effect of LVIS stent on cerebral aneurysm hemodynamics: A comparison with Enterprise stents and the Pipeline device. J. Transl. Med. 2016, 14, 1-10. [CrossRef] [PubMed]

43. Luzzi, S.; Gallieni, M.; Del Maestro, M.; Trovarelli, D.; Ricci, A.; Galzio, R. Giant and very large intracranial aneurysms: Surgical strategies and special issues. Acta Neurochir Suppl. 2018, 25-31. [CrossRef]

44. Luzzi, S.; Gragnaniello, C.; Lucifero, A.G.; Del Maestro, M.; Galzio, R. Surgical management of giant intracranial aneurysms: Overall results of a large series. World Neurosurg. 2020, 144, e119-e137. [CrossRef] [PubMed]

45. Luzzi, S.; Gragnaniello, C.; Lucifero, A.G.; Del Maestro, M.; Galzio, R. Microneurosurgical management of giant intracranial aneurysms: Datasets of a twenty-year experience. Data Brief 2020, 33, 106537. [CrossRef]

46. Yasargil, M.G. Internal carotid aneurysms, distal medial wall aneurysms and aneurysms of superior wall of internal carotid artery. Microneurosurgery 1984, 2, 58-89.

47. Nakagawa, F.; Kobayashi, S.; Takemae, T.; Sugita, K. Aneurysms protruding from the dorsal wall of the internal carotid artery. J. Neurosurg. 1986, 65, 303-308. [CrossRef]

48. Satoh, A. High risk aneurysm of the internal carotid artery: Dorsal IC Aneurysm. Surg. Cereb. Stroke 1993, 121, 467-472. [CrossRef]

49. Shigeta, H.; Kyoshima, K.; Nakagawa, F.; Kobayashi, S. Dorsal internal carotid artery aneurysms with special reference to angiographic presentation and surgical management. Acta Neurochir. 1992, 119, 42-48. [CrossRef]

50. Shimizu, H.; Matsumoto, Y.; Tominaga, T. Non-saccular aneurysms of the supraclinoid internal carotid artery trunk causing subarachnoid hemorrhage: Acute surgical treatments and review of literatures. Neurosurg. Rev. 2010, 33. [CrossRef]

51. Abe, M.; Tabuchi, K.; Yokoyama, H.; Uchino, A. Blood blisterlike aneurysms of the internal carotid artery. J. Neurosurg. 1998, 89, 419-424. [CrossRef] [PubMed]

52. Gonzalez, A.M.; Narata, A.P.; Yilmaz, H.; Bijlenga, P.; Radovanovic, I.; Schaller, K.; Lovblad, K.-O.; Pereira, V.M. Blood blister-like aneurysms: Single center experience and systematic literature review. Eur. J. Radiol. 2014, 83, 197-205. [CrossRef] 
53. Drake, C.G.; Barr, H.W.K.; Coles, J.C.; Gergely, N.F. The use of extracorporeal circulation and profound hypothermia in the treatment of ruptured intracranial aneurysm. J. Neurosurg. 1964, 21, 575-581. [CrossRef]

54. Connolly, E.S.; Solomon, R.A. Hypothermic cardiac standstill for cerebral aneurysm surgery. Neurosurg. Clin. North Am. 1998, 9 , 681-696. [CrossRef]

55. Mack, W.J.; Ducruet, A.F.; Angevine, P.D.; Komotar, R.J.; Shrebnick, D.B.; Edwards, N.M.; Smith, C.R.; Heyer, E.J.; Monyero, L.; Connolly, E.S.; et al. Deep hypothermic circulatory arrest for complex cerebral aneurysms. Neurosurgery. 2008, 62, 815-827. [CrossRef]

56. Bendok, B.R.; Gupta, D.K.; Rahme, R.J.; Eddleman, C.S.; Adel, J.G.; Sherma, A.K.; Surdell, D.L.; Bebawy, J.F.; Koht, A.; Batjer, H.H. Adenosine for temporary flow arrest during intracranial aneurysm surgery: A single-center retrospective review. Neurosurgery 2011, 69, 815-821. [CrossRef]

57. Bebawy, J.F.; Gupta, D.K.; Bendok, B.R.; Hemmer, L.B.; Zeeni, C.; Avram, M.J.; Batjer, H.H.; Koht, A. Adenosine-induced flow arrest to facilitate intracranial aneurysm clip ligation. Anesthesia Analg. 2010, 110, 1406-1411. [CrossRef] [PubMed]

58. Batjer, H.H.; Samson, D.S. Retrograde suction decompression of giant paraclinoidal aneurysms. J. Neurosurg. 1990, 73, 305-306. [CrossRef] [PubMed]

59. Flores, B.C.; White, J.A.; Batjer, H.H.; Samson, D.S. The 25th anniversary of the retrograde suction decompression technique (Dallas technique) for the surgical management of paraclinoid aneurysms: Historical background, systematic review, and pooled analysis of the literature. J. Neurosurg. 2019, 130, 902-916. [CrossRef] [PubMed]

60. I Arnautović, K.; Al-Mefty, O.; Angtuaco, E. A combined microsurgical skull-base and endovascular approach to giant and large paraclinoid aneurysms. Surg. Neurol. 1998, 50, 504-520. [CrossRef]

61. Wascher, T.M.; Spetzler, R.F.; Zabramski, J.M. Improved transdural exposure and temporary occlusion of the petrous internal carotid artery for cavernous sinus surgery. J. Neurosurg. 1993, 78, 834-837. [CrossRef] [PubMed]

62. A Kattner, K.; Bailes, J.; Fukushima, T. Direct surgical management of large bulbous and giant aneurysms involving the paraclinoid segment of the internal carotid artery: Report of 29 cases. Surg. Neurol. 1998, 49, 471-480. [CrossRef]

63. Paullus, W.S.; Pait, T.G.; Rhoton, A.L. Microsurgical exposure of the petrous portion of the carotid artery. J. Neurosurg. 1977, 47, 713-726. [CrossRef]

64. Liu, J.K.; Fukushima, T.; Sameshima, T.; Al-Mefty, O.; Couldwell, W.T. Increasing exposure of the petrous internal carotid artery for revascularization using the transzygomatic extended middle fossa approach: Acadaveric morphometric study. Oper. Neurosurg. 2006, 59, ONS-319. [CrossRef] [PubMed]

65. Mortini, P.; Mandelli, C.; Gerevini, S.; Giovanelli, M. Exposure of the petrous segment of the internal carotid artery through the extradural subtemporal middle cranial fossa approach: A systematic anatomical study. Semin. Neurol. 2001, 11, 177-188. [CrossRef] [PubMed]

66. Sekhar, L.N.; Schramm, V.L.; Jones, N.F.; Yonas, H.; Horton, J.; Latchaw, R.E.; Curtin, H. Operative exposure and management of the petrous and upper cervical internal carotid artery. Neurosurgery 1986, 19, 967-982. [CrossRef]

67. Matsukawa, H.; Tanikawa, R.; Kamiyama, H.; Tsuboi, T.; Noda, K.; Ota, N.; Miyata, S.; Takeda, R.; Tokuda, S. Risk factors for visual impairments in patients with unruptured intradural paraclinoid aneurysms treated by neck clipping without bypass surgery. World Neurosurg. 2016, 91, 183-189. [CrossRef]

68. The Clinoidal Cone. Microsurgical anatomy. Contemp. Neurosurg. 2019, 41, 6. [CrossRef]

69. De Paulis, D.; Ricci, A.; Di Vitantonio, H.; Del Maestro, M.; Raysi, S.D.; Murrone, D.; Luzzi, S.; Galzio, R.J. Cortical aneurysms of the middle cerebral artery: A review of the literature. Surg. Neurol. Int. 2017, 8, 117. [CrossRef] [PubMed]

70. Luzzi, S.; Del Maestro, M.; Elbabaa, S.K.; Galzio, R. Letter to the editor regarding “One and done: Multimodal treatment of pediatric cerebral arteriovenous malformations in a single anesthesia event". World Neurosurg. 2020, 134, 660. [CrossRef] [PubMed]

71. Luzzi, S.; Del Maestro, M.; Galzio, R. Letter to the Editor. Preoperative embolization of brain arteriovenous malformations. J. Neurosurg. 2020, 132, 2014-2016. [CrossRef] [PubMed]

72. Del Maestro, M.; Luzzi, S.; Gallieni, M.; Trovarelli, D.; Giordano, A.V.; Gallucci, M.; Ricci, A.; Galzio, R. Surgical treatment of arteriovenous malformations: Role of preoperative staged embolization. Acta. Neurochir. Suppl. 2018, 109-113. [CrossRef]

73. Raabe, A.; Nakaji, P.; Beck, J.; Kim, L.J.; Hsu, F.P.K.; Kamerman, J.D.; Seifert, V.; Spetzler, R.F. Prospective evaluation of surgical microscope-Integrated intraoperative near-infrared indocyanine green videoangiography during aneurysm surgery. J. Neurosurg. 2005, 103, 982-989. [CrossRef] [PubMed]

74. Kapsalaki, E.; Lee, G.; Robinson, J.; Grigorian, A.; Fountas, K. The role of intraoperative micro-Doppler ultrasound in verifying proper clip placement in intracranial aneurysm surgery. J. Clin. Neurosci. 2008, 15, 153-157. [CrossRef]

75. Gallieni, M.; Del Maestro, M.; Luzzi, S.; Trovarelli, D.; Ricci, A.; Galzio, R. Endoscope-assisted microneurosurgery for intracranial aneurysms: Operative technique, reliability, and feasibility based on 14 years of personal experience. Acta Neurochir. Suppl. 2018, 19-24. [CrossRef]

76. Arnaout, M.M.; Luzzi, S.; Galzio, R.; Aziz, K. Supraorbital keyhole approach: Pure endoscopic and endoscope-assisted perspective. Clin. Neurol. Neurosurg. 2020, 189, 105623. [CrossRef]

77. Luzzi, S.; Del Maestro, M.; Bongetta, D.; Zoia, C.; Giordano, A.V.; Trovarelli, D.; Dehcordi, S.R.; Galzio, R. Onyx embolization before the surgical treatment of grade III Spetzler-Martin brain arteriovenous malformations: Single-center experience and technical nuances. World Neurosurg. 2018, 116, e340-e353. [CrossRef] [PubMed] 
78. Luzzi, S.; Gragnaniello, C.; Lucifero, A.G.; Marasco, S.; Elsawaf, Y.; Del Maestro, M.; Elbabaa, S.K.; Galzio, R. Anterolateral approach for subaxial vertebral artery decompression in the treatment of rotational occlusion syndrome: Results of a personal series and technical note. Neurol. Res. 2020, 43, 110-125. [CrossRef] [PubMed]

79. Luzzi, S.; Gragnaniello, C.; Marasco, S.; Lucifero, A.G.; Del Maestro, M.; Bellantoni, G.; Galzio, R. Subaxial vertebral artery rotational occlusion syndrome: An overview of clinical aspects, diagnostic work-up, and surgical management. Asian Spine J. 2021, 15, 392-407. [CrossRef] 